\title{
Microscopic lleitis in Clinically Suspected Inflammatory Bowel Disease Patients- Can It Predict the Future?
}

Fadi Abu Baker ( $\square$ fa_fd@hotmail.com )

https://orcid.org/0000-0001-5428-7180

Jesus Alonso Z'cruz De La Garza

Hillel Yaffe Medical Center

Smadar Nafrin

Hillel Yaffe Medical Center

Amir Mari

Nazareth Hospital

Muhammed Suki

Hillel Yaffe Medical Center

\section{Baruch Ovadia}

Hillel Yaffe Medical Center

\section{Oren Gal}

Hillel Yaffe Medical Center

Yael Kopelman

Hillel Yaffe Medical Center

\section{Research article}

Keywords: Ileocolonoscopy, Inflammatory bowel disease (IBD), Microscopic ileitis (MI), Terminal ileum

Posted Date: October 4th, 2019

DOI: https://doi.org/10.21203/rs.2.15573/v1

License: (1) (1) This work is licensed under a Creative Commons Attribution 4.0 International License. Read Full License 


\section{Abstract}

Background: The implication of microscopic ileitis finding in patients referred for ileocolonoscopy for clinically suspected inflammatory bowel disease is not well defined and its correlation with clinical outcome has not been fully studied. The current study aims to determine the prognostic yield of biopsies in this setting, and to evaluate the correlation of microscopic ileitis with long-term clinical outcome.

Methods: Endoscopic reports of patients referred to our department for ileocolonoscopy in the years 2010-2016, as part of a diagnostic work-up for suspected IBD were revised. Patients with normal ileocolonoscopy were included, provided that terminal ileum biopsies were performed. Accordingly, patients were divided into normal (normal or reactive changes) and microscopic ileitis (inflammation or ileitis of any severity) groups. Both groups were followed prospectively to determine clinical outcome.

Results: 439 patients met the inclusion criteria. 64 (14.6\%) had inflammation on biopsy and were included in the microscopic ileitis group. Age and gender didn't differ significantly between groups. Overall follow up period was $6.1 \pm 2.3$ years. Patients in the microscopic ileitis group were significantly associated with Crohn's diagnosis during follow-up period compared to normal ( $19 \%$ vs $2 \%$, OR $=11.98$, $95 \% \mathrm{Cl}=4.48-32.01 ; \mathrm{p}<0.01)$. Patients with granuloma or moderate-severe ileitis on biopsy were significantly associated with Crohn's development $(100 \%$ vs $11 \%$; $P<0.01)$ compared to mild or nonspecific inflammation.

Conclusion: Microscopic ileitis finding in clinically suspected IBD is associated with increased risk of future diagnosis of crohn's disease.

\section{Background}

Ileocolonoscopy including terminal ileum biopsies have an essential role in the diagnostic workup for a suspected inflammatory bowel disease. It may aid in ruling out various infectious, inflammatory and functional disorders that may mimic inflammatory bowel disease (IBD) in presentation [1-3]. When typical or suspicious endoscopic findings are encountered, multiple representative biopsies from terminal ileum (TI) and colon segments are warranted [4].

Performing biopsies on a normally appearing colon and TI during endoscopy, however, constitutes a dilemma for practitioners who are willing to complete the diagnostic evaluation by integrating histological data, but who are aware of the possible low diagnostic yield as well as risks of a prolonged or complicated procedures [5].

While the importance of random biopsies in a normally endoscopic appearing colon in specific indications was proved in several studies [6], the role of biopsies in the terminal ileum under these circumstances is still not well defined. The predominant attitude in the literature is that biopsies from a normally appearing $\mathrm{TI}$ have a low diagnostic yield and are not routinely recommended [7-8]. 
However, the clinical setting and the indication for the procedure is of a paramount importance and may be correlated with the diagnostic yield when performing biopsies in the suitable setting[9-11]. Thus, TI biopsies may be of greatest value in patients undergoing endoscopy for known or strongly suspected Crohn's disease [12-14]. Moreover, cases of inflammatory as well as infectious disorders, diagnosed merely by biopsy with endoscopic normally-appearing TI have been demonstrated [15-16].

In our practice, during ileocolonoscopy procedure in patients referred for suspected IBD, biopsies are usually undertaken from $\mathrm{TI}$ in spite of a normal endoscopic appearance. Histopathologic examinations of these biopsies frequently show normal findings, but not uncommonly reveal changes that are consistent with chronic ileitis or other nonspecific inflammation. The significance of such microscopic ileitis (MI) and the correlation of these histological findings with long term clinical outcome are unknown and will be addressed in this study and compared to the outcome of those with normal biopsy findings to appreciate the predictive value of MI in future diagnosis of Crohn's disease.

\section{Methods}

We searched endoscopy reports to identify all patients referred to the gastroenterology department at the Hillel-Yaffe medical center, a university affiliated hospital in Israel, for ileocolonoscopy in the years 20102016 as part of a diagnostic work-up for a suspected IBD. These patients suffered from different clinical presentations such as chronic abdominal pain, diarrhea and anal complaints deemed by the referring gastroenterologist ass suspicious for IBD. Patients were included if they had normal ileocolonoscopy provided that TI biopsies were performed. Normal ileocolonoscopy denotes to findings of normal colon and TI mucosa. mild nodularity characteristic of lymphoid hyperplasia was also considered normal. Findings of erythema, friability, granularity, erosions, ulcers or strictures were considered abnormal and were not included. Moreover, only patients with a full data set, including demographic details (age, sex), indication for exam, endoscopic findings, and available biopsy results were included in the final analysis. Patients with prior colonoscopy or IBD diagnosis, as well as patients who had undergone prior colon resection were excluded.

According to the biopsy results, patients were divided into normal and Ml groups (figure 1). Normal group included patients with normal biopsy or reactive and nonspecific changes, while MI group included findings of active ileitis (normal villous architecture and polymorphonuclear or mild to moderate eosinophilic infiltrate), chronic active ileitis (distorted villous architecture; mixed inflammatory infiltrates of any severity) and granulomatous inflammation (non-caseating granuloma formation, no evidence of fungi or parasites). In order to determine the long term clinical outcome, patients in both groups were followed prospectively by tracking gastroenterology follow-up reports. Crohn's diagnosis was counted when expert gastroenterologist clearly confirm that the patient underwent subsequent follow up including recurrent endoscopic/imaging diagnostic procedures with new findings that meet the diagnostic criteria for Crohn's disease. We performed also multivariate analysis to identify independent association of age, sex and MI with crohn's disease development. In the MI group we classified patients according to inflammation severity in order to evaluate histological correlation with final outcome. 
The local institutional Helsinki ethics board in Hillel Yaffe medical center approved the study (reference number 0112-17) and granted exemption from informed consent as patients were receiving standard care without relation to the study. Data collection did not influence medical practice.

Statistical analysis:

Descriptive statistics in terms of mean, STD, and percentiles were presented to the whole parameter in the study. Differences between the two groups (normal biopsy vs evidence of inflammation in the biopsy) in the quantitative parameters (age, time of follow up) were presented by t-test. for the categorical parameters we used Fisher exact test. Multivariate analysis by logistic regression were used for prediction of Crohn's disease by age, gender and group. $\mathrm{P}<0.05$ was consider as significant. SPSS version 25 was used for the statistical analysis.

\section{Results}

Overall, the records and endoscopic reports of 537 patients who underwent ileocolonoscopy for suspected IBD and had normal findings were revised. 39 (7.2\%) patients didn't have full data set and were excluded. 59 (11\%) patients had prior colonoscopy, IBD diagnosis or colonic resection and were excluded as well. A total 439 patients were considered suitable and were included in the final analysis. Of these 64 (14.6\%) had evidence of inflammation of any severity on biopsy and were included in the MI group, while $375(85.4 \%)$ patients had unremarkable or reactive findings and were included in the normal biopsy group. Average age $(30.8 \pm 15.6$ vs $33.2 \pm 16.6, P=0.25)$ and male gender $(48.5 \%$ vs $50 \% ; P=0.89)$ didn't differ significantly between groups. Follow-up period was $5.5 \pm 2.3$ and $6.7 \pm 2.3$ years for the $\mathrm{Ml}$ and normal groups, respectively (table 1).

Patients in the Ml group were significantly associated with Crohn's disease diagnosis during follow-up period as compared to normal biopsy group ( $19 \%$ vs $2 \%$; $p<0.01)$. In multivariate analysis, finding of $\mathrm{MI}$ was highly associated with development of Crohn's as compared to normal biopsy group (OR $=11.98$, $95 \% \mathrm{Cl}=4.48-32.01 ; \mathrm{P}<0.01)$, while age $(\mathrm{OR} 0.99,95 \% \mathrm{Cl} 0.96-1.02 ; \mathrm{P}=0.68)$ or gender $(\mathrm{OR} 1.7795 \% \mathrm{Cl}$ $0.65-4.8 ; P=0.26$ ) were not. Crohn's diagnosis was recorded by referring gastroenterologist during follow-up period and all patients received active treatment.

Histological findings of patients with $\mathrm{Ml}$ are summarized in table 2. The most frequent finding was active ileitis $(61 \%)$ followed by mild active chronic ileitis (29\%). Patients with moderate-severe ileitis or granuloma finding on biopsy specimen were significantly associated with Crohn's development as compared to mild or nonspecific inflammation $(100 \%$ vs $11 \%$; $P<0.01)$.

\section{Discussion}

The current study was designed to evaluate the significance of MI and its prediction value of crohn's disease diagnosis and to assess the diagnostic yield of TI biopsy in clinically suspected but endoscopically normal patients. 
Firstly, we demonstrated that the rate of abnormal biopsy results in a normally appearing $\mathrm{TI}$ in this population was $14.5 \%$. This rate is clearly high when compared to reports from studies where ileocolonoscopies were performed for different other indications. Jonathan et al. retrospectively reviewed 414 consecutive patients with terminal ileal biopsies referred for various indications and found that when the $\mathrm{TI}$ was grossly normal, only $5.1 \%$ of biopsies were histologically abnormal and only $4.2 \%$ had significant histologic inflammation[17].xShelby D. Melton similarly Melton et al found that $5 \%$ of ileal biopsies obtained from patients with normal endoscopy in a large retrospective study had abnormal histopathologic findings [18].

Secondly, finding of MI in biopsy specimen was significantly associated with new diagnosis of Crohn's disease during follow-up period as compared to normal biopsy group $(19 \%$ vs $2 \%$; OR $=11.98,95 \% \mathrm{Cl}=$ 4.48-32.01; $\mathrm{P}<0.01)$. This association was even more significant when including merely patients with evidence of chronic inflammation on biopsy, as $40 \%$ of these patients developed Crohn's during follow-up period. Moreover, histological findings correlation with patients' outcome revealed that finding of active ileitis without chronic component or architecture distortion didn't differ significantly from patients with normal biopsy ( $5 \%$ vs $2 \% ; p=0.11$ ). We found that in all patients with mod-severe or granulomatous inflammation a diagnosis of crohn's disease was established at the end of follow-up period.

Although straightforward conclusions and recommendations for $\mathrm{Ml}$ management in this setting may be hampered by the small number of patients in the current study, these patients may benefit from unrelenting investigation with capsule endoscopy, abdominal imaging as well as close and continuous follow-up. Thus, histological findings may direct the clinician's decision regarding the necessity of further investigations or follow-up and contribute to improved patient management.

To our knowledge this is the first study to assess histological findings in this setting and evaluate its correlation with patients' outcome. Generally speaking, the significance of $\mathrm{Ml}$ and its clinical correlation is unknown. A small study by Díaz[19] linked microscopic ileitis with chronic diarrhea. However, we could find only very few studies in the literature addressing $\mathrm{Ml}$ and hence prospective studies evaluating different aspects and associations of Ml are warranted.

One main limitation of our study was the inability to access full medical investigations these patients had during follow-up period. Therefore, we couldn't have the exact percentage of patients referred for abdominal imaging and/or small bowel capsule in both groups and this might had impacted the rate of Crohn's diagnosis. However, these patients were managed by expert gastroenterologist in specific clinics and apparently received similar care.

In conclusion, in the setting of normal ileocolonoscopy of patients clinically suspected with IBD, histological findings from TI biopsies may be predictive of the clinical outcome.

\section{Declarations}


- The current study was approved by The Hillel Yaffe medical center'sinstitutional Helsinki ethics board (reference number 0112-17). The Ethics Committee waived the need to obtain consent for the collection, analysis, and publication of this non-interventional study.

- The authors confirm that this paper has not been published in its current form or a substantially similar form (in print or electronically, including on a website), that it has not been accepted for publication by another journal, and that it is not under consideration by another publication.

- Consent for publication: not applicable.

- Availability of data and materials: The datasets used and/or analysed during the current study are available from the corresponding author on reasonable request.

- Author contribution: all authors have contributed significantly and are in agreement with the content of the manuscript. FAB, SN, AM, MS, BO, JZD, OG and YK contributed to the conception, and design of the study. FAB and AM wrote the first draft of the study. FAB, SN, MS, BO and JZD performed data collection, and analysis. $O G$ and $Y K$ performed the first critical revision of the paper. All authors critically revised the article and agreed with the final version to be published.

- Conflict of Interest Statement: The authors certify that they have NO affiliations with or involvement in any organization or entity with any financial or non-financial interest in the subject matter or materials discussed in this manuscript.

- Funding: The authors confirm they received no financial support for the research, authorship, and/or publication of this article.

- Acknowledgment: none.

\section{References}

1- Yong Gil Kim and Byung Ik Jang. The Role of Colonoscopy in Inflammatory Bowel Disease. Clin Endosc. 2013 Jul; 46(4): 317-320.

2- Cuvelier C, Demetter P, Mielants H, Veys EM, De Vos M. Interpretation of ileal biopsies: morphological features in normal and diseased mucosa. Histopathology. 2001;38:1-12.

3- Rajaratnam Rameshshanker and Naila Arebi. Endoscopy in inflammatory bowel disease when and why. World J Gastrointest Endosc. 2012 Jun 16; 4(6): 201-211.

4- European evidence based consensus for endoscopy in inflammatory bowel disease

5- Byrne MF, Power DG, Keeling AN, Kay E, Murray FE, Patchett SE. Combined terminal ileoscopy and biopsy is superior to small bowel follow-through in detecting terminal ileal pathology. Dig Liver Dis. 2004;36:147-52. 
6- Yusoff IF, Ormonde DG, Hoffman NE. Routine colonic mucosal biopsy and ileoscopy increases diagnostic yield in patients undergoing colonoscopy for diarrhea. J Gastroenterol Hepatol. 2002;17:27680 .

7- Melton SD, Feagins LA, Saboorian MH, Genta RM. lleal biopsy: clinical indications, endoscopic and histopathologic findings in 10,000 patients. Dig Liver Dis. 2011;43:199-203.

8- Neilson LJ, Bevan R, Panter S, Thomas-Gibson S, Rees CJ. Terminal ileal intubation and biopsy in routine colonoscopy practice. Expert Rev Gastroenterol Hepatol. 2015 May; 9(5):567-74.

9- Melo MM, Cury PM, Ronchi LS, Gonçalves-Filho Fde A, Cunrath GS, Netinho JG. Terminal ileum of patients who underwent colonoscopy: endoscopic, histologic and clinical aspects. Arq Gastroenterol. 2009;46:102-6.

10- Koksal, Salih Boga, Huseyin Alkim, Meltem Ergun, Mehmet Bayram, Damlanur Sakiz, Osman Ozdogan, Engin Altinkaya, and Canan Alkim. How does a biopsy of endoscopically normal terminal ileum contribute to the diagnosis? Which patients should undergo biopsy? Libyan J Med. 2014; 9:10.3402

11- Yoong K.K., and Heymann T.: It is not worthwhile to perform ileoscopy on all patients. Surg Endosc 2006; 20: pp. 809-811

12- Powell N, Hayee BH, Yeoh DP, Rowbotham DS, Saxena V, McNair A. Terminal ileal photography or biopsy to verify total colonoscopy: does the endoscope agree with the microscope? Gastrointest Endosc. 2007;66:320-5.

13- Geboes K, Ectors N, D'Haens G, Rutgeerts P. Is ileoscopy with biopsy worthwhile in patients presenting with symptoms of inflammatory bowel disease? Am J Gastroenterol. 1998;93:201-6.

14- Geboes K.: The strategy for biopsies of the terminal ileum should be evidence based. Am J Gastroenterol 2007; 102: pp. 1090-1092.

15- Zwas FR, Bonheim NA, Berken CA, Gray S. Diagnostic yield of routine ileoscopy. Am J Gastroenterol. 1995;90:1441-3.

16- Misra SP, Dwivedi M, Misra V, Gupta M, Kunwar BK. Endoscopic biopsies from normal-appearing terminal ileum and cecum in patients with suspected colonic tuberculosis. Endoscopy. 2004;36:612-6.

17- McHugh JB, Appelman HD, McKenna BJ. The diagnostic value of endoscopic terminal ileum biopsies. Am J Gastroenterol. 2007;102:1084-9.

18- Lutz HH, Gaßler N, Streetz K, Sellge G, Trautwein C, Tischendorf JJ. Diagnostic value of routine ileum biopsy in patients with chronic diarrhoea- a prospective monocentric study. Z Gastroenterol. 2013 Dec;51(12):1377-82. 
19- Díaz Santisteban M. Microscopic ileitis as a cause of chronic diarrhea: study of cases and controls. Rev Gastroenterol Peru. 2007 Jul-Sep;27(3):310-8.

\section{Tables}

Table 1. Baselines characteristics and patient outcome in both study groups.

\begin{tabular}{cccc}
\hline Patients & Normal biopsy (N=375) & Microscopic Ileitis (N=64) & P Value \\
\hline Age (years) & $30.8 \pm 15.6$ & $33.2 \pm 16.6$ & $\mathrm{P}=0.25$ \\
\hline Sex (male) & $182(48.5 \%)$ & $32(50 \%)$ & $\mathrm{P}=0.89$ \\
\hline Follow-up (years) & $6.7 \pm 2.3$ & $5.5 \pm 2.3$ & $\mathrm{P}=0.08$ \\
\hline Crohn's diagnosis & $7(2 \%)$ & $12(19 \%)$ & $\mathrm{P}<0.01$ \\
\hline
\end{tabular}

Table 2. Biopsy findings and its correlation with Crohn's disease diagnosis during follow-up period in microscopic ileitis group.

Biopsy findings

Active ileitis

Mild chronic active ileitis

Moderate-severe chronic active ileitis

Granuloma +/- ileitis of any severity
Patients number N(\%) Crohn's diagnosis N(\%)

$39(61 \%)$

$2(3.1 \%)$

$19(29 \%)$

$4(21 \%)$

$3(5 \%)$

$3(100 \%)$

$3(5 \%)$

$3(100 \%)$

\section{Figures}




\section{7 ileocolonoscopies for suspected IBD}

98 excluded
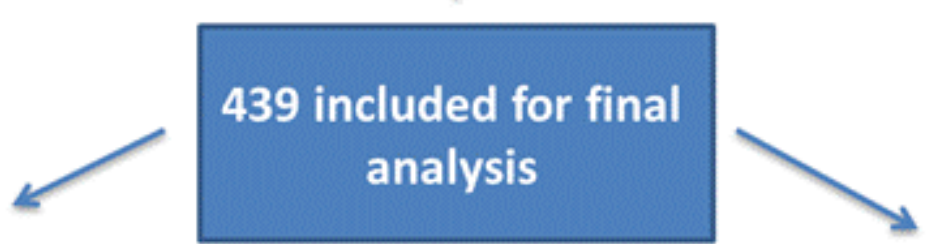

\section{$375(85.4 \%)$ \\ Normal/reactive}

\section{$64(14.6 \%)$ \\ Microscopic ileitis}

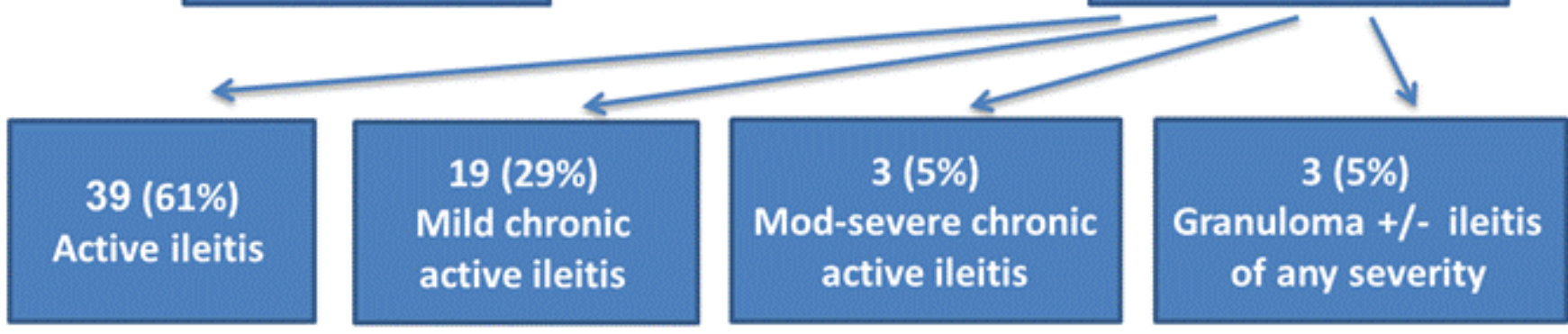

Normal villous architecture and $P M N+/$ - mild-mod eosinophilic infiltrate

\section{Distorted villous} architecture; mixed mild inflammatory infiltrates.
Distorted villous architecture; mixed mod-severe inflammatory infiltrates.
Non-caseating granuloma, no evidence of fungi or parasites + inflammatory infiltrates of any severity

\section{Figure 1}

study population and groups definition. 